\section{Prognosis in Hodgkin's Disease}

Q.-Does complete recovery from Hodgkin's disease ever occur, and if so, after what interval, during which the patient is free from signs and symptoms, can it be assumed to have taken place? If complete recovery is possible, in what percentage of cases does it occur?

A.- There is no evidence that complete recovery from Hodgkin's disease ever occurs. About $80 \%$ of the subjects die within three years of the onset of symptoms, and only about $5 \%$ live more than five years. In any large series of cases there will be a few with a duration up to ten years, and survival for twenty-five years has been recorded. It is not possible to make an accurate prediction in the individual patient. Even though the patient has been completely free of symptoms for months or years, the disease may suddenly reappear in an acute and rapidly fatal form.

\section{Intramuscular Injection of Iron}

Q.-In the treatment of microcytic anaemias, is there a physiologically effective preparation of iron for intramuscular injection?

A.-No, there is not. Iron is one of those substances which are much more toxic by injection than by mouth, and the minimum effective dose (25 mig. Fe a day) is very close to the maximum tolerated dose. Immediately after the injection of this amount of iron the patient experiences unpleasant symptoms such as feelings of warmth, nausea, vomiting, palpitation, and precordial constriction. It is conceivable that a preparation might one day be found from which the iron is gradually released, as the active arsenic is released from neoarsphenamine, but the intense physiological activity of iron and the absence of channels of excretion do not make the prospect very hopeful.

\section{LETTERS, NOTES, ETC.}

\section{Possible Contagiousness of Cancer}

Dr. J. H. Douglas Webster (London, W.1) writes: The expert answering the question on this subject (March 31, p. 468), who says that " cancer is no more contagious than broken legs," seems to base this verdict (the orthodox one) on the observation that a chicken sarcoma does not spread to chickens in the same pen; and on the scepticism statisticians have about "cancer houses." But should not a distinction first be drawn between "closed" and "open " cancers? A cancer shut off in an otherwise normal organ (as breast or liver) cannot be contagious: but may not an open cancer (of skin, lip, cervix, or rectum) possibly be contagious? In patients occasional infection of the opposite lip or labium has been observed; and infection of an abdominal or breast scar during operation (as in a stitch-hole) has often been noted. Patients with skin cancer sometimes apparently infect themselves by scratching: I have now a patient with multiple skin cancers of the face, probably due to this cause. Then I know of two instances of lung cancers in husband and wife; one of a wide ulcerated abdominal wall sarcoma where the husband after months of helping with the dressings had a histologically similar spindle-celled sarcoma of the foot; a rectal case in which a young maidservant had apparently become infected from her mistress by using her enema syringeconfirming two similar instances noted by Bland-Sutton (from Macewen, Tumours, 1922 ed., p. 268); and there are probably more uterine cervix and penile cases than "chance" would account for (Leighton, 1932; Desaive, 1933). There are also the two striking instances, almost certainly infective, detailed in my book Periodicity and Cause of Cancer (1940, p. 109).

For contagion to be possible an abrasion on the skin or mucous membrane would seem necessary (as scratching, or rough use of an enema syringe), but given such an opportunity can all open cancers be considered $100 \%$ non-contagious? There may be only a decimal percentage involved, but is it scientific to ignore this possibility? In any case is it wise to draw rigid conclusions about a disease the cause of which is not yet known? Should cancer prove in the end to be a virus disease (see Oberling's recent Riddle of Cancer), open cases of cancer should be considered possible sources of infection, though to a much less degree than many other virus diseases, as warts.

\section{John Knyveton's Diary}

Prof. Miles Phillips (Carmarthen) writes: I am interested in your reply to the question on the probable origin of the Diary of a Surgeon in the Year 1751-1752. I would venture to amplify it by quoting a note written by myself in December, 1941, on the fly-leaf of my own copy of this book: "I have no doubt that this Diary is an artefact, largely based on the Memoir of my own Life, written in 1779," by Thomas Denman, M.D. (1733-1815), and on the Continuation of that Memoir, signed B, and written, no doubt, by his son-in-law, Matthew Baillie. Convincing evidence of this is to be found by comparing statements on pages, 4, 5, 6, 147, 313-16 of the Diary with statements on pages lix, Ixviii-lxxii, and lxxviIxxviii of the Memoir and its Continuation, which are to be found in the seventh edition (London, 1832) of Thomas Denman's Introduction to the Practice of Midwifery. The mind of a reader of the Diary is somewhat prepared for the possibility, by a reference, in the "editor's note," to "this being an age of impudent literary allusions."

Dr. J. F. BlacketT (Bath) writes: I have made the following additional criticisms of Knyveton's Diary (April 21, p. 579): they are, of course, of little importance except from the point of view of establishing authenticity. "The Village of Hestley, Kent". (p. 9) is not mentioned in the gazetteers I have been able to consult. In England, Sept. 2, 1752, was followed by Sept. 14, to adjust to the Gregorian Calendar; and the dates Sept. 3-13 inclusive on pages 270 to 283 had no existence. The change, however, may not have been observed by ships at sea. If Aug. 30 (p. 269) was a Sunday, as it was, and the change to the Gregorian reckoning $\frac{\sigma}{\sigma}$ ignored, then Nov. 7 (p. 306) would be Saturday, not Sunday as $\mathbb{D}$ stated-and so would Nov. 14 and 21 (pp. 307 and 309). In England they were Tuesdays.

\section{Malaria and Syphilis}

Brig. T. E. Osmond (Ashford, Middlesex) writes: Whilst $\rightarrow$ being the last person to question your omniscience in most matters, $\omega$ I cannot agree that "there is no evidence that malarial infection has any therapeutic effect on a Treponema pallidum infection "O (B.M.J., April 28, p. 618). Surely the well-known effect of induced?. malaria on G.P.I. gives the lie to this. Your inquirer might beinterested to read an article by A. A. Rosenburg (J. Lab. clin. Med., $1945,30,149)$, who claims to be able to distinguish between positive serum reactions due to syphilis and malaria respectively by precipitating syphilis reagin with ammonium sulphate.

** Is not the emphasis on "infection"? And is not the success- N ful treatment of G.P.I. by malaria due to its pyrogenic effect? ED., B.M.J.

The Fxaminer's Attitude

Dr R. G. BLAIR (New Buckenham) writes: I he letter from Mr. H. I. Deitch (March 31, p. 470) on the examiner's attitude prompts me to support the writer's views from a different angle. For the past fifteen months it has been my lot to study specialists opinions in many hundreds of different cases. The gross differencescr of opinion expressed by specialists on many individual cases leave me with the impression that if either specialist were being examinedo by the other for a higher degree he would be ignominiously failed? I have long felt that our system of examination as a qualifying pro cess leaves much to be desired, and I would suggest that the furthern we get from purely clinical diagnosis, and the more we depend or mechanical aids to investigation, the greater will be the margin of our inexactitudes.

\section{9th General Hospital}

Col. James O'Grady writes from Stoneacre, Swinton, Manchester $:$ Please allow me to bring to the notice of past and present member of 19th General Hospital the fact that an Old Comrades Associationis in process of formation. I should be glad if any officers, nursings officers, warrant officers, or other ranks, who are interested, and ares or have been on the strength of the unit, would send me a postcard, giving rank, name, and present address; I will then forward a form of application for membership.

\section{Corrections}

We must apologize to Dr. P. Ellinger for errors made in sending his letter "Detection of Nicotinic Acid Deficiency" (May 12, p. 678 to the press: 2nd paragraph, line 12, should have read, "Najjar inf his latest paper did not propose ..."; ante-penultimate line of 2 nd paragraph, "Nicotinamide is not considered"; 3rd paragraph, 7th line from end, "nicotinamide" should have read "nicotinamide. methochloride"; the last line but one of the 4th paragraph should have read " $(20$ to $50 \%$ of the values found in healthy peoplen were ..."

Dr. R. Cruickshank writes: May I correct some ambiguities in the report on my remarks at the R.S.M. on penicillin in urinare infections (Journal, May 12, p. 674). (1) The last sentence on paragraph 2 should read, "and therefore reliance must not be placed ..." (2) In the table, the sensitivity of coliform organisms should be 15-30 units, not 30-60. The word "ratio" should b] omitted. The point of this table was to show that with a dails dosage of 100,000 units of penicillin a urinary concentration of 30-40 units per c.cm. could be obtained, and therefore penicilli could be used in the treatment of urinary infections due to $S t r_{0}$ faecalis, B. proteus, and some of the coliform organisms. In me concluding remarks I said I had recently visited a Canadian hospitas in this country where they were using highly purified penicillin, and it was the custom there to use procaine as the patients objected i the local analgesic were omitted. Omission of the night doses couk be done in the treatment of more localized infections, but not in septicaemic conditions.

Mr. Herbert Brown (Worthing) writes to correct two errors in his letter of May 5 (p. 645): (1) he entered U.C.H. in 1881, not 1880 ; and (2) was house-physician to Ringer in 1886, not 1881. 